\title{
COMPARISON OF TEMPERATURE COEFFICIENT OF STANDARD INDUCTOR BY MEASURING CHANGE IN INDUCTANCE AND RESISTANCE
}

\author{
M. A. Ansari, Jyotsana and Anil Kishore Saxena \\ National Physical Laboratory \\ (Council of Scientific and Industrial Research) \\ LF \& HF Impedance Standards, \\ Dr. K.S. Krishnan Marg, New Delhi 110012, India \\ aksaxena@nplindia.org
}

\begin{abstract}
$\underline{\text { Abstract }}$
Standard inductors manufactured by General Radio (GR) are widely used by NMIs. The temperature coefficient for these standard inductors is $30 \pm 5$ $\mathrm{ppm} /{ }^{\circ} \mathrm{C}$, as per manufacturer. NPL India (NPLI) had earlier determined the temperature coefficient of standard inductors by measuring change in inductance. Now by measuring change in resistance, temperature coefficient of inductors is re-determined. Temperature coefficients determined from the two methods are reported here.

\section{Introduction}

Temperature coefficient of standards plays a major role in precision measurements. NPLI had earlier determined the temperature coefficient of standard inductors of value $1 \mathrm{mH}$ (GR 1482, three numbers) by measuring change in inductance using PC based setup $[1,2]$. The temperature coefficient of these inductors in the temperature range of $22{ }^{\circ} \mathrm{C}$ to $27^{\circ} \mathrm{C}$ was between 42 to $47 \mathrm{ppm} /{ }^{\circ} \mathrm{C}$ with deviation of \pm 5 $\mathrm{ppm}$. These results were in agreement with the result reported in [3] and [4].
\end{abstract}

As per specification of Inductors, the temperature coefficient of inductors can be determined by measuring DC resistance of inductors. It is mentioned that $1 \%$ increase in resistance, produced by temperature increase of $2.54{ }^{\circ} \mathrm{C}$ corresponds to $0.0076 \%$ increase in inductance.

Therefore it was decided to verify the previous results by measuring change in dc resistance of inductors.

\section{Methodology}

NPLI had earlier used the setup based on difference voltage measurement (Method I) to measure change in inductance and thus determine temperature coefficient of inductors [2] at $1 \mathrm{kHz}$. Change in inductance of test inductor $\mathrm{L}_{\mathrm{x}}$ is measured with respect to auxiliary inductors $\mathrm{L}_{\mathrm{A}}$. The $\mathrm{L}_{\mathrm{A}}$ is $10 \mathrm{mH}$ inductor of GR make. Initially both the test inductor and auxiliary inductor were kept at constant temperature for more than 24 hours in separate air baths, developed at NPLI, with a temperature controlled within $\pm 0.2{ }^{\circ} \mathrm{C}$. Temperature of $\mathrm{L}_{\mathrm{A}}$ was kept constant throughout the experiment. Then the temperature of enclosure of test inductor was changed by $1{ }^{\circ} \mathrm{C}$. The software controls the Lock-in Amplifier and records the difference voltage at an interval of 30 minutes for 24 hours. The software calculates change in inductance from measured difference voltage and also records the changes in inductance values. Measurements were repeated for the temperature range from $22{ }^{\circ} \mathrm{C}$ to 27 ${ }^{\circ} \mathrm{C}$. Experiment was repeated with other two $1 \mathrm{mH}$ inductors.

NPLI has currently determining the temperature coefficient of these inductors by measuring the change in resistance with respect to temperature (Method II). These inductors were kept in a commercial air bath, whose temperature stability is $\pm 0.05^{\circ} \mathrm{C}$. The air bath temperature was set at a particular temperature for about 24 hours and resistance of the inductor was measured by using Fluke make 8846 A, 61/2 digits precision multimeter. Measurements were taken at an interval of 30 minutes. Process was repeated for $1{ }^{\circ} \mathrm{C}$ and $2.54{ }^{\circ} \mathrm{C}$ temperature change.

\section{$\underline{\text { Results }}$}

Graph and results obtained by two methods are shown in table 1 and fig. 1 to fig.5.

\begin{tabular}{|c|c|c|}
\hline \multirow{2}{*}{ Sr. No. } & \multicolumn{2}{|c|}{$\begin{array}{c}\text { Temperature Coefficient (in ppm) } \\
\text { with deviation }\end{array}$} \\
\cline { 2 - 3 } & Method I & Method II \\
\hline 18892 & $46 \pm 5$ & $26 \pm 5$ \\
\hline 18577 & $42 \pm 5$ & $29 \pm 5$ \\
\hline 19570 & $47 \pm 5$ & $31 \pm 5$ \\
\hline
\end{tabular}

Table 1. Temperature Coefficient of 1mH, GR 1482 standard inductors 


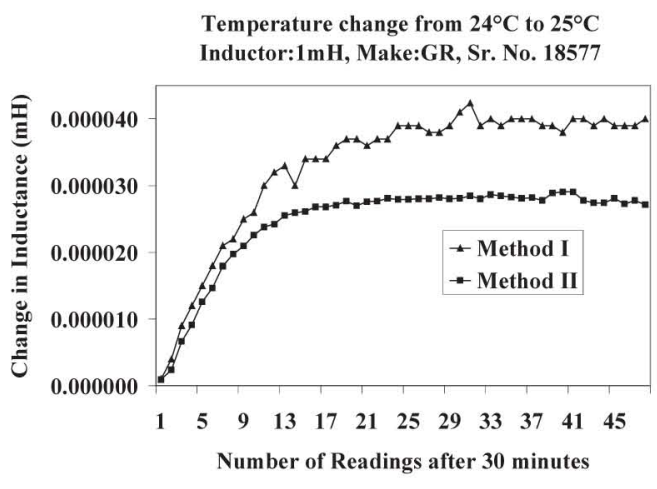

Fig.1 Change in Inductance for $1^{\circ} \mathrm{C}$ temperature change

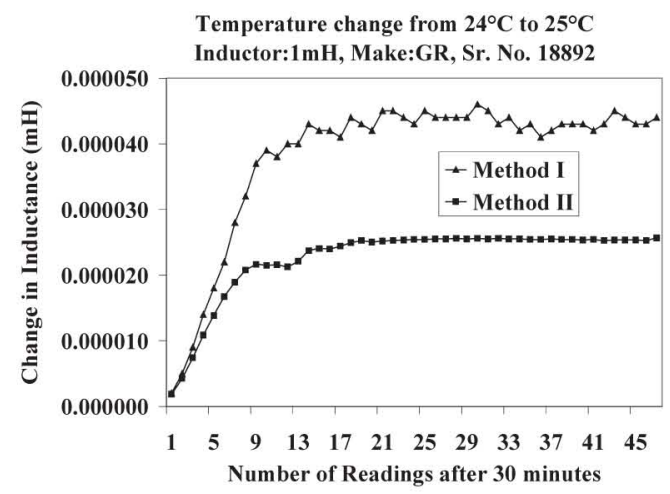

Fig.2 Change in Inductance for $1^{\circ} \mathrm{C}$ temperature change

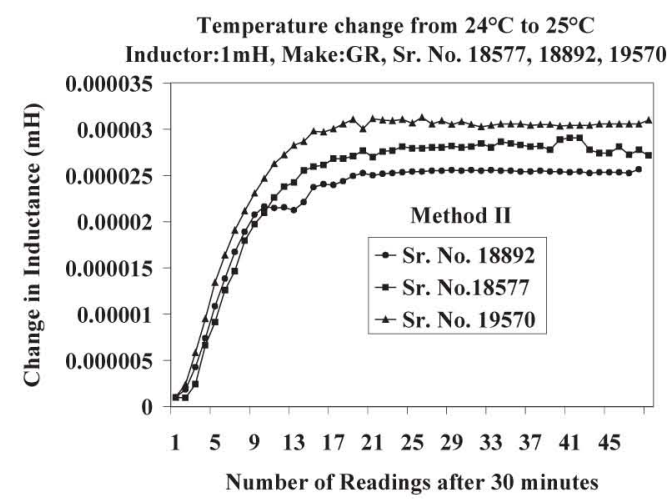

Fig.3 Change in Inductance for $1^{\circ} \mathrm{C}$ temperature change

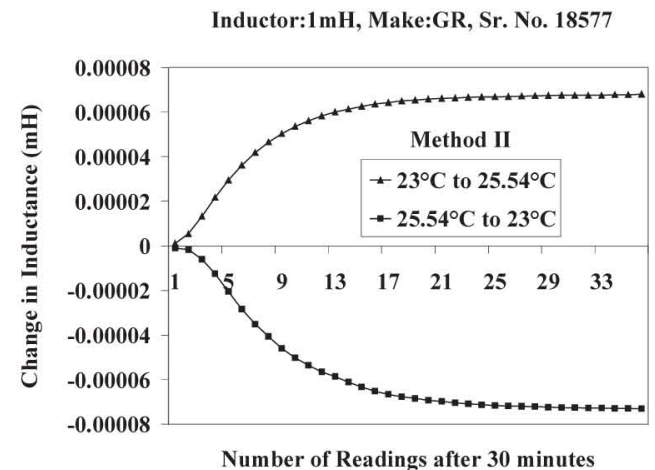

Fig.4 Change in Inductance for $2.54^{\circ} \mathrm{C}$ temperature change
Inductor:1 mH, Make:GR, Sr. No. 18892

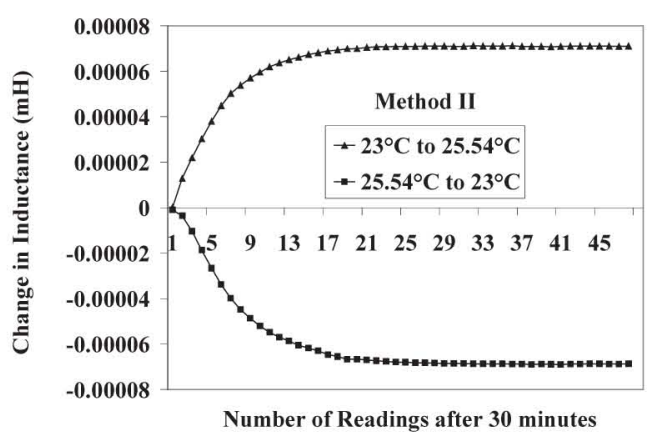

Fig.5 Change in Inductance for $2.54^{\circ} \mathrm{C}$ temperature change

\section{Conclusion}

It is clear from both the methods that inductors take 10 to 12 hours to stabilize against change in temperature and the temperature coefficient is different for different inductors of same value.

The temperature coefficient obtained by method I is agreed with results reported in [3], [4]. It is different from temperature coefficient determined by method II.

\section{Acknowledgement}

The authors are grateful to Prof. R. C. Budhani, Director NPL for permission to publish this paper and Dr. P. Banerjee, Head Electrical and Electronic standards for his constant encouragement.

\section{$\underline{\text { References }}$}

[1] A.K. Saxena and Mohd. Saleem "An Automatic Bridge for Calibration of Inductance based on Difference Voltage Measurements" CPEM 1998 Conf. Digest, pp 500-501, held at Washington, USA from July 6-8, 1998

[2] Shally Sharma, A.K. Saxena and Mohd. Saleem "A PC Based setup to Determine Temperature Coefficient of Standard Inductors Using Difference Voltage Measurement Technique" CPEM 2008 Conf. Digest, pp 570-571 held at Colorado, USA, from June 08 to June13, 2008

[3] A. Fiebiger and K. Droge " Bestimmung des Temperature Koefficient von Induktivitatsnormallen des Type GR 1482" PTB Mitteilungen, vol. 94, pp 10-14, 1984.

[4] Kewal Krishan, R.N. Dhar and S.L. Dahake "Determination of Temperature Coefficient of Inductance Standards" MAPAN- Journal of Metrology Society of India, vol 5, no.2, pp. $107-110,1990$. 